\title{
Ritmos com sentido. Educar o corpo, a alma e 0 espírito em escolas Waldorf
}

\author{
Meaningful Rhythms. Educating body, soul and spirit \\ in Waldorf schools
}

Raquel PEREIRA HENRIQUES

Faculdade de Ciências Sociais e Humanas(FCSH)

Universidade Nova de Lisboa / Instituto de História Contemporânea (IHC)

RESUMO: Este artigo insere-se no âmbito do projeto INOVAR - Roteiros da inovação pedagógica: escolas e experiências de referência em Portugal no século XX, financiado pela Fundação para a Ciência e a Tecnologia (FCT) desde maio de 2016. Pretende-se analisar historicamente modelos pedagógicos ou experiências educativas que tenham surgido como inovadoras, ou que ainda representem formas de escolarização alternativas ao modelo escolar mais comum, perceber que metodologias de trabalho eram ou são utilizadas, que fundamentos e percursos caracterizam cada uma dessas instituições.

O Jardim de Infância São Jorge é uma das escolas que faz parte desse conjunto estudado. É um estabelecimento de ensino particular e cooperativo, sem fins lucrativos, fundado em 1984 segundo os princípios da pedagogia Waldorf criada por Rudolf Steiner. Foram utilizados textos deste filósofo, diversos estudos teóricos, a documentação de arquivo na escola, testemunhos orais de educadores e pais e, também, a observação direta e participante de algumas atividades.

PALAVRAS-CHAVE: Pedagogia Waldorf; Antroposofia; Ritmo; Educação Tripartida; Educação Integral

ABSTRACT: This paper had been written under the INOVAR project - Itineraries of pedagogical innovation: reference schools and experiences in Portugal in the twentieth century (20162019), funded by the Portuguese Foundation for Science and Technology, since May 2016. This project's aim is to develop a historical analysis of pedagogical models and educational experiences that have emerged as innovative, or which consist of forms of schooling that represent an alternative to the common school model. The project focuses on the methodologies that were or are still used in these cases, as well as on the foundations and trajectories that characterize these institutions.

The São Jorge Kindergarten is one of the cases studied. It is a private and cooperative, non-profit educational institution founded in 1984 according to the principles of Rudolf Steiner's Waldorf pedagogy. We used texts from this philosopher, several theoretical studies, ar- 
chival records of the school, oral testimonies of educators and parents, as well as direct and participant observations of some activities.

KEY WORDS: Waldorf Pedagogy; Anthroposophy; Rhythm; Threefold Education; Integral Education

\section{Jardim de Infância São Jorge}

Em Portugal a primeira escola Waldorf abriu oficialmente em 29 de Setembro de 1984. Foi um jardim de infância que ainda hoje existe, fundado pela Associação de Pais para 0 desenvolvimento de um ensino segundo Rudolf Steiner - o Jardim de Infância São Jorge, em Alfragide, próximo de Lisboa.

Num folheto promocional então elaborado refere-se que nestas escolas "baseadas nos princípios de Rudolf Steiner pretende-se encontrar o equilíbrio entre a aquisição de conhecimentos e a prática de atividades artísticas e manuais. Procura-se, assim, possibilitar o desenvolvimento das faculdades intelectuais bem como de uma vida afetiva sã na expressão de cada indivíduo". Inclui-se também nesse folheto uma frase de Steiner considerada lapidar: "o objetivo fundamental é formar seres humanos livres, com vastos e ricos interesses, que saibam conscientemente dirigir as suas vidas"1.

A partir do momento em que o Jardim de Infância São Jorge entrou em funções, como um estabelecimento de ensino particular e cooperativo sem fins lucrativos, a preocupação seguinte seria a de conseguir administrá-lo convenientemente e, também, fazer crescer aquela iniciativa pedagógica, ou seja, desenvolvê-la "através de atividades que, divulgando a pedagogia de Rudolf Steiner, fossem chamando pais para o seu seio. Assim tem acontecido e neste momento, a Associação de Pais já tem projetadas outras atividades que possibilitem o saudável crescimento do Jardim de Infância S. Jorge"2.

Os objetivos eram muito claros: administrar o Jardim de Infância de forma pedagógica adequada e economicamente viável; dar-Ihe continuidade criando uma outra escola que viesse a receber crianças mais velhas e divulgar a pedagogia de Rudolf Steiner através da realização de diferentes diligências que envolvessem pais, amigos, membros da Sociedade Antroposófica em Portugal e pessoas ligadas a outras escolas Waldorf fora do País - encontros sobre temas educativos, palestras sobre algumas festividades, sobre a importância dos contos de fadas, o tipo de brinquedos mais adequados e a sua elaboração, etc. ${ }^{3}$.

O Jardim de Infância São Jorge foi, portanto, o resultado da iniciativa de alguns pais, "habituais frequentadores da Associação Waldorf de Lisboa e desejosos de terem uma

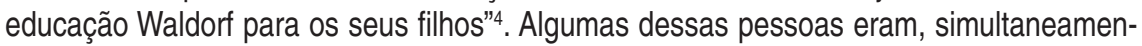

\footnotetext{
${ }^{1}$ Jardim de Infância São Jorge, Arquivo. Folheto promocional - Um Jardim de Infância Segundo Rudolf Steiner, não datado.

2 Jardim de Infância São Jorge, Arquivo. História da Associação de Pais, duas folhas datilografadas, não datadas.

${ }^{3}$ Jardim de Infância São Jorge, Arquivo. Calendarização de atividades/encontros para o ano de 1985, documento datado de 18 de março de 1985.

${ }^{4}$ Jardim de Infância São Jorge, Arquivo. História da Associação de Pais, duas folhas datilografadas, não datadas.
} 
te, sócias da Associação Waldorf de Lisboa e membros da Sociedade Antroposófica em Portugal ${ }^{5}$ e surgem os nomes de Luís Filipe Quintas, economista e o primeiro presidente da associação de pais; João Manuel Castella, professor de liceu; Christel Makosh, antiga educadora de infância no "Jardim Infantil da Escola Alemã de Lisboa (Deutsche Schule Lissabon) de 01 de outubro de 1955 até 30 de setembro de $1959^{\prime \prime}$ e que acabaria por ser diretora pedagógica do São Jorge durante alguns anos, de 1991 a 2000; Ana Maria Abreu, educadora de infância, também sócia da Sociedade Antroposófica em Inglaterra7; Maria Celeste Mendonça, educadora de infância8; João Pedro Rosado, arquiteto; Nuno Rocha, psicólogo e também sócio da Sociedade Antroposófica na Suíça; Danuta Wojciechowska, educadora e artista plástica9 ${ }^{\text {. }}$

A abertura oficial ocorreu em 29 de setembro de 1984, mas só em 10 de dezembro de 1991 é que a Direção-Geral do Ensino Básico e Secundário emitiu uma autorização definitiva de funcionamento:

Nos termos do $\mathrm{n}^{\circ} 5$ do artigo $28^{\circ}$ do Decreto-Lei $\mathrm{n}^{\circ}$ 553/80, de 21 de novembro e ao abrigo do despacho de 26 de agosto de 1991, é concedida autorização definitiva de funcionamento de um estabelecimento de ensino particular e cooperativo denominado Jardim de Infância S. Jorge frequentado por alunos dos sexos masculino e feminino, em coeducação, sito em Estrada de Alfragide, Casa Vestfália, concelho de Amadora, distrito de Lisboa, cuja entidade proprietária é a Associação de Pais para o desenvolvimento de um ensino segundo Rudolf Steiner. $O$ estabelecimento fica autorizado a ministrar os seguintes cursos: pré-escolar - vinte e uma crianças em regime de planos e programas oficiais. É dirigido por Christel Makosch ${ }^{10}$.

No mês seguinte, em 6 de janeiro de 1992 a mesma Direção-Geral diz que "foi autorizada a denominação de "Jardim de Infância São Jorge»"11 e só muito mais tarde se

\footnotetext{
${ }^{5}$ Jardim de Infância São Jorge, Arquivo. Sócios fundadores da Associação de Pais para o desenvolvimento de um ensino segundo Rudolf Steiner, folha datilografada, não datada.

${ }^{6}$ Jardim de Infância São Jorge, Arquivo. Documentos oficiais. Certificado da Escola Alemã de Lisboa (Deutsche Schule Lissabon), datado de 04 de outubro de 1990.

${ }^{7}$ De Ana Maria dos Santos Severino de Abreu há dois diplomas no arquivo da escola, um deles do Ministério da Educação e Cultura, datado de 1979, confirmando a autorização para o exercício de funções no ensino primário particular e outro passado pelo Wynstones Kindergarten Training Course (Member of International Movement for Steiner Kindergartens) em Gloucester. Este último documento diz que Ana Abreu "has completed the kindergarten training course for the year september 1982 to july 1983". No programa do curso surgem duas rubricas, "arts and crafts" (music, eurythmy, speech formation, painting, modelling, woodwork, spinning, toymaking) e "theory" (studies in Anthroposophy, child development, work with parents, health aind illness, foundation for the daily work in the kindergarten) - ver Jardim de Infância São Jorge, Arquivo. Documentos oficiais.

${ }^{8}$ Há um diploma de Maria Celeste Aires de Mendonça referindo que é educadora e professora de infância, datado de 1958. Em conjunto com Ana Abreu acabou por fazer a mesma formação no Wynstones Kindergarten Training Course, em Gloucester. Em 1984 um outro diploma do Ministério da Educação refere que estava autorizada a exercer ensino infantil particular - ver Jardim de Infância São Jorge, Arquivo. Documentos oficiais.

${ }^{9}$ De Danuta Wojciechowska existe no arquivo da escola um diploma do Emerson College (an adult centre of training \& research based on the work of Rudolf Steiner), em Sussex, passado em 1984, dizendo que tinha "completed a training in Waldorf (Steiner) Education" entre Setembro de 1983 e Junho de 1984 - ver Jardim de Infância São Jorge, Arquivo. Documentos oficiais.

${ }^{10}$ Jardim de Infância São Jorge, Arquivo. Documentos oficiais. Autorização de funcionamento emitida pelo Ministério da Educação / Direção-Geral do Ensino Básico e Secundário, 1991.

${ }^{11}$ Jardim de Infância São Jorge, Arquivo. Documentos oficiais. Autorização de funcionamento emitida pelo Ministério da Educação / Direção-Geral do Ensino Básico e Secundário, 1992.
} 
procedeu à regularização da creche. Embora funcionasse desde os finais da década de noventa, o processo de legalização foi demorado e o alvará data de 2011.

Nas duas primeiras décadas a escola passou por períodos muito atribulados do ponto de vista económico, atendendo sobretudo ao reduzido número de crianças inscritas e, por conseguinte, a uma crónica insuficiência de verbas ${ }^{12}$ mas atualmente estão inscritas trinta e seis crianças, dos doze meses aos sete anos ${ }^{13}$, ou seja, durante o primeiro septénio, designação do próprio Rudolf Steiner.

Regressando a 1984, o jardim infantil abriu apenas com nove crianças dos três aos sete anos. Ana Abreu era a principal educadora e responsável pela condução da parte pedagógica. Tinha estado em Gloucester a fazer uma formação como "kindergarten teacher", no Emerson College and Wynstones Kindergarten Training Course (Member of International Movement for Steiner Kindergartens), formação que não foi de imediato reconhecida em Portugal pelo Ministério da Educação. Danuta Wojciechowska surgiu também como educadora mas só ali trabalhou durante aquele ano, tendo em conta o reduzido número de crianças inscritas e, consequentemente, de verbas e, ainda, porque considerou que 0 modelo pedagógico poderia ser socialmente mais interventivo, mais eficaz na abrangência de outro tipo de pessoas que não apenas aquelas que ali conviviam e que acabavam por fazer parte de um nicho com muitas proximidades culturais, económicas e sociais ${ }^{14}$.

É certo que o processo de criação da escola foi muito complexo e foi a generosidade de muitos que possibilitou a sua abertura. A começar pela cedência das instalações, a habitação de dois pisos e cave, rodeada por um jardim, a Casa Vestfália onde ainda hoje permanece. Pertencendo a Carl-Wilhem Busse, um alemão de quem Christel Makosh era procuradora, poderia ser arrendada por uma verba reduzida desde que ali funcionasse uma escola Waldorf, ou seja, uma escola que implementasse os princípios pedagógicos defendidos por Rudolf Steiner ${ }^{15}$.

Atualmente a Casa Vestfália pertence a uma instituição intitulada Casa de Santa Isabel, Instituto de Pedagogia Curativa e Socioterapia, sita em São Romão, Seia, que se rege por princípios da Antroposofia e que é, também, um exemplo de espaços que Steiner in-

\footnotetext{
${ }^{12}$ Percebe-se pelas atas da direção que em 1984 as doações chegaram a corresponder a $72 \%$ das verbas e que as propinas apenas cobriam o restante. A insuficiência de verbas foi sempre um problema com o qual a direção da escola foi obrigada a lidar e, por diversas vezes, houve ordenados em atraso. A situação financeira regularizou-se sobretudo a partir de 2008, na direção de Paula Martinez, muito também devido à progressiva estabilidade do número de inscrições - ver Jardim de Infância São Jorge, Arquivo. Atas - Atas da Direção, 1984-2014.

${ }^{13}$ Informação oral prestada por Paula Martinez. Com formação inicial em Direito, é a atual diretora do Jardim de Infância São Jorge, cargo que ocupa desde 2008. Participou num seminário intitulado S. Jorge, o jardim tranquilo (pedagogia Waldorf), no Instituto de Educação, Universidade de Lisboa, em 27 de novembro de 2017.

${ }^{14}$ Ver Jardim de Infância São Jorge, Arquivo. Atas da Direção, Ata no 28 de 20 de junho de 1985.

Informações orais prestadas por Danuta Wojciechowska. Sócia da Associação Waldorf de Lisboa é artista plástica e trabalhou no Jardim de Infância São Jorge como educadora durante um ano letivo, de 1984-1985. Foi entrevistada telefonicamente a 18 de julho de 2017, durante cerca de $1 \mathrm{~h}$.

${ }^{15} \mathrm{~A}$ verba correspondia a $20.000 \$ 00$ mensais - ver Jardim de Infância São Jorge, Arquivo. Documento datilografado, não datado [1985], 4 páginas + anexos, onde se fala do enquadramento administrativo e, também, das "condicionantes financeiras".
} 
centivou a criar, ao preocupar-se com o modo de concretizar uma pedagogia curativa para diversos tipos de deficientes e/ou inadaptados ${ }^{16}$. O Jardim de Infância São Jorge continua a pagar ao novo proprietário uma renda simbólica, dentro do espírito de solidariedade e entreajuda que Steiner sempre incentivou ${ }^{17}$.

Muitos princípios pedagógicos defendidos por Steiner estão presentes no quotidiano desta escola e falar-se-á um pouco mais à frente de aspetos concretos, quando se especificam atividades desenvolvidas no primeiro septénio, ou seja, nos primeiros sete anos de vida, também referidos como o "primeiro nascimento". Mas sintetizam-se desde já algumas características identificadoras, nomeadamente o facto de ser uma associação sem fins lucrativos, em que a participação dos pais é fulcral no quotidiano da escola, para a concretização de mediações que se vão realizando em dias específicos como a festa dos ofícios, por exemplo.

Por outro lado, há uma partilha efetiva de tarefas entre educadoras, elementos da direção e auxiliares, que dividem democraticamente o que é mais agradável e o que é menos apetecível. Há também uma preocupação permanente com a regularidade dos ritmos, com a harmonia, a segurança e a tranquilidade que se transmitem às crianças nas atitudes $e$ nos diálogos ${ }^{18}$. Os teatros, os contos, as histórias e as brincadeiras, bem como todas as formações que são feitas para os pais e familiares têm como objetivo principal uma educação integral, harmoniosa, que respeita não só os ritmos da natureza exterior como os ritmos de crescimento individuais. Uma das preocupações fulcrais desta pedagogia e, por conseguinte desta escola, é o auxílio que se pode e deve proporcionar para alcançar um saudável crescimento físico, emocional e espiritual das crianças, nada apressando. Não se ultrapassam etapas porque tal como a natureza que nos rodeia, tudo tem o seu tempo e cada criança vai compreendendo, serenamente, a melhor forma de se relacionar consigo própria e com os outros ${ }^{19}$.

\section{Ritmos com sentido ou o sentido dos ritmos}

Rudolf Steiner nasceu em Kraljevec, então território austríaco, em 27 de fevereiro de 1861 e morreu em Dornach, na Suíça, em 30 de março de 1925. Steiner ficou sobretudo

\footnotetext{
${ }^{16}$ Ver Casa de Santa Isabel, Instituto de Pedagogia Curativa e Socioterapia em http://www.casasantaisabel.org/ pt/, acesso em fevereiro de 2018.

${ }_{17}$ Jardim de Infância São Jorge, Arquivo. Correspondência. Carta não datada [2010] que faz referência ao valor da renda paga ao proprietário: 142,91€ mensais.

18 Teresa Abrantes, mãe e encarregada de educação de uma criança que frequentava o Jardim de Infância São Jorge em 2017, explicou aliás no seu testemunho oral que uma das razões pelas quais inscreveu os seus filhos naquela escola foi a tranquilidade, a inexistência de gritos. Foi entrevistada em 11 de julho de 2017, durante cerca de $1 \mathrm{~h}$.

${ }^{19}$ Estas particularidades ficaram muito bem expressas nos testemunhos orais quer de Paula Martinez, quer de Felipa Vieira. Felipa Vieira teve formação inicial na Escola Superior de Educadores de Infância Maria Ulrich, é a atual diretora pedagógica do Jardim de Infância São Jorge. Participou num seminário intitulado S. Jorge, o jardim tranquilo (pedagogia Waldorf), no Instituto de Educação, Universidade de Lisboa, em 27 de novembro de 2017.
} 
conhecido por ter sido o fundador da Antroposofia e, também, da pedagogia Waldorf que tem por base a imagem do Homem proposta pela Antroposofia.

De uma forma excessivamente sintética, a Antroposofia visava o conhecimento pleno do Homem, enquanto ser triplamente constituído, simultaneamente físico, anímico e espiritual2 $^{20}$.

Y el método, el sistema de educación de la escuela Waldorf se apoya en una concepción de la vida, la ciencia espiritual antroposófica, que está enteramente cimentada sobre un conocimiento equilibrado de cuerpo, alma y espíritu del hombre. Y, mediante este conocimiento equilibrado de los tres aspectos de la naturaleza humana, quiere evitar toda unilateralidad ${ }^{21}$

Steiner refletiu profundamente na organização da sociedade, nos seus aspetos económicos, jurídico-políticos, culturais e espirituais. Esse seu olhar esteve desde sempre imbuído de princípios fundamentais, os princípios de igualdade, de fraternidade e de liberdade, que deviam e devem continuar a reger a atividade humana na sua essência. Todos estamos intrinsecamente dependentes uns dos outros, todos somos iguais e merecemos os mesmos cuidados, todos devemos ter um pensamento autónomo e liberto de peias, devidamente fundamentado. Considerava essencial que uma pessoa conhecesse aprofundadamente as estruturas sociais em que se inseria, porque só dessa forma poderia conseguir intervir nelas e, eventualmente, contribuir para a sua alteração, se tal se justificasse.

Subjacente a estas preocupações permaneciam os ideais de autonomia e liberdade individual, que só um trabalho interior de autoconhecimento poderia desenvolver, ou seja, uma pessoa só conseguiria intervir se conhecesse o meio mas, também, a sua própria personalidade e as suas capacidades porque a liberdade é, essencialmente, um processo interior, de tomada de conhecimento de si. A unir estes fundamentos, Steiner considerava como essenciais a fraternidade, a solidariedade e o respeito pelo próximo, o trabalho conjunto, a intervenção social para proporcionar condições semelhantes a todos e auxiliar quem de facto estivesse dependente de outros para o seu bem-estar e sobrevivência ${ }^{22}$.

Em 1919 Rudolf Steiner teve a possibilidade de idealizar e criar uma nova escola para os filhos dos operários da fábrica de tabaco Waldorf-Astoria, em Stuttgart e fê-lo também com base nesses princípios da Antroposofia. Ficaria conhecida como Escola Livre Waldorf e acabaria por inspirar a criação de muitas outras e servir de base à que é designada como "pedagogia Waldorf". Inovadora para o seu tempo, aquela escola deveria ser frequentada por alunos de diferentes origens sociais e, também, de diferentes sexos. A coeducação passou a ser uma característica identitária, bem como a partilha e a colaboração entre

\footnotetext{
${ }^{20}$ Ver Rudolf Steiner, World History in the light of Anthroposophy - and as a foundation for knowledge of the human spirit. Eight Lectures given in Dornach, 24 th to $31^{\text {st }}$ December, 1923 (London: Anthroposophical Publishing Company, 1950) e, também, Rudolf Steiner, Anthroposophie. L'Homme et sa recherche spirituelle. 9 conférences faites à Dornach du 19 janvier au 10 février 1924 (Genève: Éditions Anthroposophiques Romandes, 1989, 3ª ed.). ${ }^{21}$ Rudolf Steiner, La educación del niño desde el punto de vista de la Antroposofía. Metodología de la enseñanza y las condiciones vitales de la educación - cinco conferencias pronunciadas en Stuttgart del 8 al 11 de abril de 1924. (Madrid: Editorial Rudolf Steiner, 1991), 54.

${ }_{22}$ Ver, por exemplo, Rudolf Steiner, L'Être Humain dans l'ordre social. Individu et communauté. Trois conférences prononcées à Oxford du 26 au 29 août 1922 (Paris: Centre Triades, 1990).
} 
alunos de diversas idades e, também, de educadores. Além do mais, previa doze anos de escolaridade "com um programa de estudo o mais completo possível no qual se mistur[avam] harmonicamente as atividades intelectuais, artísticas e práticas"23.

Compreende-se que tendo em conta a sua pedagogia libertária e progressista tenham sido fechadas pelos nacionais socialistas ${ }^{24}$ para só reapareceram depois da II ${ }^{a}$ Guerra Mundial, multiplicando-se um pouco por toda a Alemanha e, de forma gradual, em muitos outros países.

Atentemos nos ideais de liberdade e de fraternidade, na preocupação em adquirir uma consciência plena de si próprio e dos seus atos, em desenvolver uma multiplicidade de interesses que contribuam para uma "integração total"25 ou uma educação integral: foram estas preocupações que, de uma maneira geral, estiveram sempre presentes no pensamento filosófico de Steiner e nas suas propostas pedagógicas.

Steiner justifica amplamente a constituição tripartida do ser humano tendo em conta que todos somos, simultaneamente, seres sensoriais, seres anímicos e seres espirituais, e que o equilíbrio ou o desequilíbrio dessa tripartição interfere positiva ou negativamente em cada um de nós. A saúde física, mental e emocional, tudo aquilo que nos transmite conforto e tranquilidade depende do respeito harmonioso entre essas partes, entre o corpo, a alma e o espírito. Essa harmonia é ritmo, é uma perpétua cadência porque a vida que nos é exterior, tal como tudo o que se passa no nosso corpo, na nossa vida interior, é ritmo também².

Mas porquê falar em ritmos e em harmonia? Porque partindo de uma reflexão sobre fenómenos naturais que se vão repetindo numa cadência mais ou menos regular como 0 movimento dos planetas, a sucessão anual das estações, os dias e as noites, a regeneração periódica da vegetação, etc., Steiner demonstrou em numerosos textos a relação intrínseca entre o Cosmos, a Terra e o Homem.

Estabeleceu íntimas conexões entre os fenómenos físicos que acontecem no nosso organismo e de que dependemos para viver como, por exemplo, a respiração, a digestão, a circulação do sangue, os movimentos peristálticos, o sono ou a vigília, com os ciclos regulares de vinte e quatro horas, os ciclos diários que retomam a sua cadência de sete em sete dias, estabelecendo uma sincronia entre o nosso ritmo interno e o próprio Cosmos ${ }^{27}$.

\footnotetext{
${ }^{23}$ Warren Ashe; Alan Hall; Ron Jarman; Christopher Marshall; Brien Masters, Educação Waldorf - Introdução à Educação Waldorf de Rudolf Steiner ([Venda Nova]: Bertrand Editora/Casa de Santa Isabel, 1991), 2.

${ }^{24}$ Ver Rudolf Steiner, Les bases spirituelles de l'éducation. Neuf conférences faites au Mansfield Collège Oxford, Août 1922 (Paris : Centre Triades, 1951), 8.

${ }^{25}$ Warren Ashe et. al., Educação Waldorf - Introdução à Educação Waldorf de Rudolf Steiner, 2.

${ }^{26}$ Rudolf Steiner, Pédagogie et connaissance de l'homme. 8 conférences faites aux professeurs de l'école Waldorf, Stuttgart, 12 au 19 juin 1921 (Genève: Editions Anthroposophiques Romandes, 1981), 26.

${ }^{27}$ Ver Rudolf Steiner, Select Lectures. (s.d.) (Disponivel em https://archive.org/stream/RudolfSteinerSelect Lectures_201611/Rudolf\%20Steiner/Rudolf\%20Steiner\%20-\%20Select\%20Lectures\#page/no/mode/2up, acesso em fevereiro de 2018), 281-282.
} 
Fazendo o Homem parte integrante do que o envolve, pode dizer-se que nele reside a própria natureza e, por isso, nele reside também o divino ${ }^{28}$.

Tomar consciência de si e dos outros, refletir permanentemente no que se diz e faz contribuirá, certamente, para uma vida mais equilibrada e saudável, tornando-nos aptos a trabalhar para um desenvolvimento espiritual ${ }^{29}$, tendo em consideração que "a harmonia é o ideal de um futuro remoto" 30 e, também, a selecionar os melhores alimentos, a rejeitar aquilo que sentimos que nos é prejudicial, a escolher as sequências mais adequadas de trabalho e de lazer, de acordo com o nosso metabolismo.

O organismo humano depende, intrinsecamente, dos ritmos: "todo o ser humano está predisposto ao ritmo. Por isso também é bom, em todo o decorrer da vida - com o qual nos relacionamos ao educar e ensinar crianças -, poder atentar à repetição rítmica" ${ }^{\prime \prime}$.

Mas como consegui-lo? Utilizando com as crianças aquilo que Steiner chama "uma sensibilidade instintiva para o ritmo, a rima, o compasso; e uma sensibilidade para a forma interior da poesia, [a] sua beleza intrínseca"32 tendo em conta que todos nós somos, já foi dito, organismos que se organizam em processos sistemáticos e que dependem da organização harmoniosa desses processos para sobreviver.

Só evoluímos se conseguirmos ir incorporando as emoções, o sentimento. Aprendemos primeiro por empatia e depois porque reorganizamos os novos conceitos que aprendemos, integramo-los e refletimos sobre eles. Tudo é emoção ou tudo é, inicialmente, emoção. A linguagem, como o pensamento, implica uma formulação que Steiner associa à cadência rítmica da música e da poesia ${ }^{33}$.

Se a criança é para Steiner um órgão sensorial, nas creches e jardins de infância Waldorf o trabalho de cada dia e a organização dos horários, ou dos ritmos como habitual-

\footnotetext{
${ }^{28}$ Ver Rudolf Steiner, L'Impulsion du Christ et la Conscience du Moi. Conférences faites par Rudolf Steiner, publiées d'après des notes non revues par l'Auteur (Paris: Triades, 1956, $2^{\underline{a}}$ ed.), 34 e 35.

${ }^{29}$ Ver Rudolf Steiner, A moral teosófica. Três conferências proferidas em Norrköping em 28, 29 e 30 de maio de 1912 aos membros da Sociedade Teosófica na Escandinávia (São Paulo: Editora Antroposófica, 1985), 53.

${ }^{30}$ Idem, 54.

${ }^{31}$ Rudolf Steiner, Pédagogie et connaissance de l'homme, 60.

${ }^{32}$ Rudolf Steiner, A arte da educação III - Discussões Pedagógicas. Quinze colóquios seminarísticos e três palestras sobre o currículo, realizados em Stuttgart de 21 de agosto a 6 de setembro de 1919, por ocasião da fundação da Escola Waldorf Livre. (s.d.) (Disponivel em https://gepepidotnet3.files.wordpress.com/2011/02/ steiner_-_a_arte_da_educac3a7c3a3o_iii.pdf, acesso em fevereiro de 2018), 123.

${ }^{33}$ Ver Rudolf Steiner, $A$ arte da educação II - Metodologia e didática no ensino Waldorf. Catorze conferências, proferidas em Stuttgart de 21 de agosto a 5 de setembro de 1919, por ocasião da fundação da Escola Waldorf Livre. (s.d.) (Disponivel em https://pt.scribd.com/document/290799013/Rudolf-Steiner-A-Arte-da-educacao-II-pdf, acesso em janeiro de 2018), 10, 15 e 30.

Numa outra obra especifica: "It is important to realize the value of children's songs, for example, as a means of education in early childhood. They must make pretty and rhythmical impressions on the senses; the beauty of sound is of greater value than the meaning. The more alive the impression on eye and ear the better. Dancing movements in musical rhythm have a powerful influence in building up the physical organs, and this should also not be undervalued" - Rudolf Steiner, The Education of the Child and Early Lectures on Education. Hudson (N.Y.: Anthroposophic Press, 1996), 23.
} 
mente são designados nesta pedagogia, é estruturada de uma forma orgânica, tendo em conta a constituição física e as necessidades básicas de acordo com os momentos do dia ou do ano, em sintonia com a própria natureza.

Num artigo promocional do Jardim de Infância São Jorge, incluído numa revista para "pais e filhos", dizia-se, em 1998:

Os ritmos da natureza (...) são aplicados ao desenvolvimento da criança e na rotina diária do jardim infantil. Na prática, isto traduz-se, por exemplo, em se sentarem para ouvir uma história e em seguida irem ao ar livre brincar, depois sentarem-se para pintar e assim por diante. A sequência repete-se diariamente, mudando apenas o conteúdo das atividades. As histórias que são contadas (uma de manhã e outra diferente à tarde) são repetidas durante uma semana e as músicas também se repetem. A repetição, os horários e a harmonia no ritmo das atividades dão segurança à criança, afirma uma brochura sobre a educação Waldorf ${ }^{34}$.

Dezanove anos depois, uma educadora infantil daquela mesma escola especifica-nos que as pausas antes da refeição ou depois dela são propositadas, não só para marcar tempos diferentes, mas para introduzir outras etapas de forma segura e tranquila. Até porque no ritmo diário estabelecido depois da refeição vem o momento da sesta, antecedido pelo conto: "a história vai variando de quatro em quatro semanas. (...) É preferível a mesma história todos os dias durante algum tempo, durante quatro semanas, e essa é uma característica desta escola (...). Acho preferível ler a mesma história durante algum tempo. Eles não se cansam"35.

Ali os dias são quase sempre organizados da mesma forma: depois da receção da manhã há a roda rítmica (de que se falará mais à frente), a atividade propriamente dita (que varia de dia para dia embora mantendo a regularidade), a brincadeira livre no jardim, 0 almoço, o momento do conto, a sesta, o lanche, de novo a brincadeira livre no jardim até à saída pela mão de familiares. As atividades do dia são organizadas semanalmente, durante a manhã: na segunda-feira há a ajuda na cozinha, na terça-feira há a aguarela, na quarta-feira há o fabrico do pão, na quinta-feira a modelagem em cera de abelha e na sexta-feira a jardinagem, sequência semanal que se repete ao longo do mês, ao longo do ano, interrompido apenas em determinados momentos relacionados com algumas festividades que são celebradas como, por exemplo, o Advento, o Dia de Reis, a Festa dos Ofícios, o Pentecostes.

O ritmo é regularidade e harmonia e essa regularidade contribui, em primeiro lugar, para a aquisição de uma sensação de conforto e de tranquilidade. Como as crianças mais pequenas aprendem por imitação e sequência, acredita-se que toda esta frequência e

\footnotetext{
${ }^{34}$ Mariza Figueiredo, "Em Paz e Harmonia", Pais \& Filhos, no 89, (1998), 46-48.

${ }^{35}$ Entrevista com Rita Barranquinho em 14 de julho de 2017. Rita Barranquinho teve formação inicial na Escola Superior de Educadores de Infância Maria Ulrich e é, atualmente, educadora no Jardim de Infância São Jorge. Foi entrevistada nos dias 11 e 14 de junho de 2017, durante cerca de 2h30m.

Repare-se que as quatro semanas em que a história é narrada correspondem, no fundo, a um dos ciclos referidos por Steiner, que considerava as vinte e quatro horas, os sete dias e as quatro semanas como núcleos temporais fundamentais que se organizam em anos, onde se repetem e reorganizam alguns fenómenos biológicos e também lunares.
} 
repetição acabam por fortalecer, trazer segurança, organizar o pensamento, a vontade ${ }^{36}$. Reforça-se um sentimento de segurança individual muito útil para poder mais tarde adaptar-se às novidades e à perturbação que por vezes essas novidades introduzem. Os ritmos são resilientes, tal como a natureza e, desse modo, podem contribuir para o fortalecimento dessa capacidade e de resistência à frustração. Em segundo lugar é importante que cada um consiga aprender a organizar os seus tempos, em função do que precisa fazer e, por isso, a relevância de interiorizar essa distribuição temporal e espacial desde muito cedo.

Por outro lado, para crianças mais velhas que já desenvolvem trabalho escolarizado a partir dos sete anos, as tarefas são organizadas por projetos que têm determinada duração, os chamados "períodos pedagógicos" ${ }^{37}$. Se o que interessa é desenvolver, numa determinada altura do ano letivo uma aprendizagem em Matemática, com determinados exercícios práticos e teóricos, pode acontecer que durante três ou quatro semanas se insista sobretudo, e durante a manhã, nessas tarefas da Matemática, reservando-se a tarde para atividades motoras, artísticas ou laboratoriais. Numa fase seguinte, o trabalho reorganizar-se-á depois para uma outra aprendizagem numa disciplina diferente ou que reúna várias, em colaboração concertada sobre conteúdos que podem e devem ser analisados de diferentes perspetivas para uma melhor compreensão do tema, permitindo que se vá desenvolvendo um determinado projeto ao longo de um certo tempo. A aprendizagem da Matemática, que aparentemente fora colocada de parte, será depois retomada e 0 facto de se relembrar contribui para uma melhor concentração e, consequentemente, para resultados mais eficazes.

Nunca se espartilha o horário em sequências iguais, o que significa que não há 0 conceito de hora letiva. $\mathrm{O}$ trabalho não é interrompido só porque acabou uma hora ou uma hora e meia e é a partir de um ciclo de três ou quatro semanas que se trabalham os conteúdos de uma determinada área científica e disciplinar: "se introducen ejercicios, resúmenes sobre las narraciones del maestro, pequenas evaluaciones com el fin de proporcionarles a los alumnos sa satisfacción de saber o el estímulo para practicar mejor y com más aplicación"38. Aqueles conteúdos serão recuperados mais tarde e essa paragem, segundo Steiner, é fundamental para interiorizar, absorver, compreender. Tudo se vai assim ajustando e reajustando periodicamente, em intervalos regulares, tendo em conta o que é necessário planificar ${ }^{39}$.

Os cuidados com a organização dos ritmos permanecem visíveis a partir dos sete anos, mas como durante a manhã há mais facilidade para as tarefas intelectuais, o dia escolar inicia-se com as matérias que exigem a necessidade de saber e compreender,

\footnotetext{
${ }^{36}$ Também estas características da pedagogia Waldorf foram claramente enunciadas por Felipa Vieira, por Paula Martinez e, ainda, por Christel Makosh, nos testemunhos orais que prestaram. Christel Makosh foi sócia fundadora da Associação Waldorf de Lisboa e educadora de infância. Ocupou vários cargos de direção e foi também diretora do Jardim de Infância São Jorge. Foi entrevistada em 25 de maio de 2016 durante cerca de 1h30m.

${ }^{37}$ Ver Frans Carlgren (1989). Pedagogia Waldorf: una educacion hacia la libertad. La pedagogía de Rudolf Steiner. Informes del Movimiento Internacional de las Escuelas Waldorf (Madrid: Editorial Rudolf Steiner, 1989), 109-110.

38 Ibidem, 109.

${ }^{39}$ Ver Rudolf Steiner, La educación del niño desde el punto de vista de la Antroposofía, 107.
} 
analisar e abstrair. Depois seguem-se as disciplinas que requerem uma constante repetição rítmica: línguas estrangeiras, euritmia e desporto, música e religião. Os trabalhos manuais, a jardinagem, as experiências científicas, etc. devem ficar para o final da manhã ou para a tarde ${ }^{40}$.

A repetição para os alunos mais velhos verifica-se, sobretudo, na organização deste tipo de horário por ciclos ou "períodos pedagógicos" que, sendo diferente ao longo do ano tem, por outro lado, características comuns, deixando para as manhãs tarefas mais abstratas e para a tarde tarefas mais práticas.

Pode pois afirmar-se que os ritmos são organizados com um sentido muito próprio que é, fundamentalmente, o de respeitar a natureza da criança e do adolescente, não apressando nada, não impondo de forma abrupta, observando, procurando estimular a imaginação, a fantasia, acompanhando o crescimento físico, anímico e espiritual daquela pessoa e contribuindo para que se desenvolva a capacidade de autoconhecimento, de autonomia, de liberdade de pensamento e de expressão.

Uma característica relevante desta pedagogia é, sem dúvida, a de que há tempo, a de que tem de haver tempo para aprender a ser e a conhecer.

\title{
Educar o corpo, a alma e o espírito em escolas Waldorf
}

\begin{abstract}
Assim, toda [a] atividade educacional e docente é dirigida inicialmente a um campo bem elevado, ou seja, o ensino da respiração e do ritmo corretos na alternância entre sono e vigília. As regras que orientarão [0] nosso ensino e [a] nossa pedagogia não terão, evidentemente, a finalidade de adestrar a respiração, ou o sono e a vigília. Tudo isso permanecerá em segundo plano. As regras que conheceremos serão medidas concretas, mas deveremos ter uma profunda consciência do que fizermos. Ao ministrar à criança esta ou aquela matéria curricular deveremos, pois, estar conscientes de atuarmos, de um lado, sobre a integração da alma espiritual no corpo físico e, de outro, sobre a integração da corporalidade orgânica na alma espiritual (...) Ensinando e educando, estabeleceremos a correta harmonia entre a respiração e o mundo espiritual ${ }^{41}$.
\end{abstract}

A educação para Steiner deve ser, no fundo, um processo pelo qual se aprenda a relacionar o corpo físico com o emocional e o intelectual ou, dito de outra forma, com a vontade, o sentimento, o pensamento. $O$ educador tem de lidar com essas "forças anímicas" e mãos, coração e cabeça são progressivamente incorporados num trabalho que olha para a criança e o adolescente de forma integradora e que, dependendo da sua idade, está mais apta ora a utilizar as mãos (para fazer algo - sobretudo nos primeiros sete anos), ou o coração (o sentimento - dos sete aos catorze anos fundamentalmente) ou a cabeça (a

\footnotetext{
${ }^{40}$ Ver Frans Carlgren (1989), Pedagogia Waldorf: una educacion hacia la libertad, 106.

${ }^{41}$ Rudolf Steiner, $A$ arte da educação I - $O$ estudo geral do Homem, uma base para a Pedagogia (curso de Antropologia Geral para professores Waldorf). Catorze conferências, proferidas em Stuttgart de 21 de agosto a 5 de setembro de 1919, por ocasião da fundação da Escola Waldorf Livre. (s.d.) (Disponível em https://pt.scribd. com/document/217523444/Rudolf-Steiner-A-Arte-da-Educacao-I, acesso em fevereiro de 2018), 10-11.
} 
elaboração de raciocínios progressivamente mais complexos - dos catorze aos vinte e um anos ${ }^{42}$ relacionando, de uma forma progressiva e equilibrada esses três domínios.

Esse trabalho do educador parte assim do conhecimento profundo da natureza humana, num processo que nunca é apenas ditado pelo intelecto, mas que tem por base uma certa religiosidade no entendimento do mundo e que, por isso, tem em conta ritmos diários, semanais, mensais e anuais ${ }^{43}$.

O educador é assim, e também, um modelador e um organizador de ritmos, de preferência de uma forma harmoniosa, despertando os sentidos para a magia dos sons, para as cores, para a importância das formas, das linhas, desenvolvendo um trabalho que deve ser também pensado artisticamente, para que aqueles a quem a sua atividade se dirige consigam adquirir "uma consciência estética do mundo"44.

O educador deve igualmente ter em conta que na atividade educativa que desenvolve trabalhará em função da bondade, da verdade e da beleza, porque é isso que verdadeiramente interessa às crianças e estudantes, que ficam despertos para as escolhas que considerarem mais adequadas ${ }^{45}$.

Educar o querer, o sentir e o pensar é, assim, uma das tarefas mais significativas do pedagogo, senão mesmo a primeira, ramificando-se depois em muitas outras que vão sendo desenvolvidas. Na verdade, educar é, para um educador Waldorf, contribuir para que a criança aprenda a conhecer-se a si própria equilibrando o ser tripartido que é. Por isso também um educador Waldorf autointitula-se um acompanhante que deve sobretudo aprender a reconhecer os sinais, as capacidades, os talentos. Deve ser, primeiro que tudo, um observador de si próprio e autoeducar o seu temperamento, tendo em conta que as suas atitudes, a sua forma de ser, estar, falar, influenciam quem os rodeia, sobretudo os mais pequenos, muito suscetíveis ao meio envolvente e, por conseguinte, às reações do educador e à relação fundamental que se estabelece entre ambos, em que a criança tendencialmente imita 0 adulto que dele se ocupa ${ }^{46}$.

Tendo em conta as fases evolutivas da criança e do adolescente, Steiner definiu três septénios que correspondem, no fundo, a três fases consideradas fundamentais para 0 desenvolvimento integral do ser humano a que também chamou "nascimentos" ou, ainda, "épocas da vida"47: até aos sete anos, idade em que geralmente surge a segunda dentição, período em que se é muito recetivo, onde se combina "instinto e sobretudo imitação"48; dos sete aos catorze anos, em que há uma predisposição para uma "aprendizagem em

\footnotetext{
${ }^{42}$ Ver Patricia Quiroga Uceda, La recepción de la pedagogía Waldorf en España. Dissertação de Doutoramento policopiada. (Madrid: Universidad Complutense de Madrid, 2015), 116.

Ver também Rudolf Steiner, La educación del niño desde el punto de vista de la Antroposofía, 40.

${ }^{43}$ Ver Rudolf Steiner, Select Lectures, 281-282.

${ }^{44}$ Rudolf Steiner, Pédagogie et connaissance de l'homme, 92.

${ }^{45}$ Rudolf Steiner, La educación del niño desde el punto de vista de la Antroposofía, 125-126.

${ }^{46}$ Rudolf Steiner, La educación del niño desde el punto de vista de la Antroposofía, 57-59 e 65.

47 Idem, 22 e 66.

${ }^{48}$ Warren Ashe et. al., Educação Waldorf - Introdução à Educação Waldorf de Rudolf Steiner, 4.
} 
sentido formal" e em que se "experimenta e expressa a vida por meio de sentimentos mais definidos"49 e, por fim, dos catorze aos vinte e um anos, a adolescência, onde mais do que pensar elaboradamente se é capaz de um raciocínio crítico, de juízos valorativos, de construções criativas elaboradas e contextualizadas.

Ora não só há diferenças físicas óbvias ao longo dessas três fases como, também, um desenvolvimento psíquico que se complexifica com o passar dos anos. Para o educador Waldorf mantém-se como fundamental a necessidade de não ultrapassar etapas, ou mesmo de não as apressar: não vale a pena escolarizar atividades numa criança pequena, com menos de sete anos, porque a intelectualização prematura é prejudicial até para o seu desenvolvimento físico e emocional. Se ela não está ainda preparada para um determinado tipo de organização e de tarefa mais exigente do ponto de vista da concentração ou da abstração, insistir poderá contribuir para o surgimento de desequilíbrios futuros. Nesta idade são as atividades artísticas, o teatro, o conto de fadas, as canções que têm significado e que, por isso mesmo, poderão ajudar no crescimento físico, emocional e espiritual da criança.

Não apressar nada, porque tudo tem o seu tempo, pode ser outro dos lemas desta pedagogia.

\section{Primeiro nascimento}

O «Jardim de Infância S. Jorge» (...) segue a orientação pedagógica fundada por Rudolf Steiner - a pedagogia Waldorf. Esta pedagogia defende que é no reconhecimento e respeito pelos processos de desenvolvimento da criança, mais do que nas matérias, que o adulto mais pode ajudá-la no seu desenvolvimento ${ }^{50}$.

Portanto, na "idade inicial do homem", como chamou Steiner ao primeiro septénio, sempre que a criança chega é cumprimentada individualmente pelo educador - é o primeiro momento do dia na escola. Junta-se às outras e brincam durante algum tempo, dependendo da hora a que vão chegando.

O segundo momento do dia mais significativo é a roda rítmica ou a roda dos bons dias. Dirigida pelo educador, corresponde a um movimento de contração e caracteriza-se por uma canção entoada por todos, colocados em roda, com as mãos dadas. É um cântico que é, sobretudo, um bom dia à natureza e aos animais mas, também, a cada um em particular.

As mãos vão-se soltando, os braços levantam-se e rodam em movimentos suaves, contribuindo para a inspiração e a expiração, para a tomada de consciência do seu corpo. É um momento fundamental porque tranquiliza as crianças e que acaba com a frase entoada por todos: "no céu há estrelas, na terra há flores, tudo revela o mesmo amor. No meio estás para as ligar, se fores capaz de tudo amar"51.

\footnotetext{
${ }^{49}$ Idem, 5.

${ }^{50}$ Jardim de Infância São Jorge, Arquivo. Regulamento do Jardim de Infância S. Jorge, [2006-2007] - a data é uma anotação feita a lápis.

${ }^{51}$ Estes momentos foram presenciados por mim na própria escola.
} 
Realiza-se então a atividade do dia, uma outra ocasião de contração e que pode ser pintura com aguarela ou fabrico de pão ou jardinagem ou ajuda na cozinha... A fruta trazida de casa por cada família, previamente descascada e partida, é distribuída por todos - 0 recipiente vai rodando e cada criança, sentada, vai tirando um gomo de laranja, uma rodela de banana, um pedaço de maçã, etc.

Tudo é arrumado e passa-se para a brincadeira livre no jardim. Mesmo quando chove (desde que a chuva não seja muito intensa) vestem oleados, calçam galochas e vão para 0 exterior. É agora uma outra fase, esta de expansão, na qual o adulto pouco interfere sendo, sobretudo, um mediador de conflitos. A água, a terra, o fogo e o ar estão, de certa forma, permanentemente presentes e as crianças convivem naturalmente com esses elementos.

Antes do almoço e depois de terem lavado as mãos, o educador tem a necessidade de voltar a recentrar as crianças, conduzindo-as a uma contração física e emocional. 0 almoço pode ser no exterior (se houver alguma festividade associada e se houver pais a participar) mas é, quase sempre, no interior. Uma vela é acesa, as crianças dão as mãos e entoam uma outra canção:

Terra que estes frutos deu

Sol que os amadureceu

Nobre terra

Nobre sol

Nós jamais vos esqueceremos

Abençoada refeição

Bom apetite

Obrigada.

A alimentação nestas escolas é muito cuidada. No Jardim de Infância São Jorge, em particular, é lacto-vegetariana e o almoço é confecionado diariamente pela diretora com produtos biológicos. Seguindo o princípio de que também somos o que comemos e que o corpo se autoeduca com uma alimentação adequada é fundamental consumir produtos sãos, que estimulem os nossos instintos de preservação, com grande abundância de fruta, de vegetais e leguminosas integradas na sopa e nas saladas.

Deitam-se e ouvem uma história que, como já foi dito, se repete todos os dias durante cerca de quatro semanas, propositadamente. Dormem ou, pelo menos, descansam para voltar a brincar livremente no jardim e a lanchar.

Os seus dias são portanto pautados por momentos de contração, intervalados com outros de expansão, cadenciadamente ${ }^{52}$. A creche ou o jardim de infância deverão proporcionar as alternâncias entre a vigília e o sono, a contração e a expansão, de modo a que 0 corpo físico e o corpo espiritual evoluam em simultâneo, por um mútuo respeito, ganhando confiança, num trabalho em que as emoções são tão relevantes como o pensamento mais elaborado mas que contém, sempre, emoção.

\footnotetext{
${ }^{52}$ Este aspeto muito característico foi claramente explicado por Felipa Vieira no seu testemunho.
} 
O ritmo entre atividades concentradas e jogo livre preside a todos os dias; igualmente se vivencia durante todo o ano o ritmo das estações. Contos, marionetes, pintura, modelagem, jogos de roda, música, fabricação de pão... tudo está concebido de acordo com a idade. Observar as próprias tradições culturais, vivenciar a natureza, com as suas festividades de cada estação, são aspetos que merecem a maior atenção $0^{53}$

Pode dizer-se que até aos sete anos a criança aprende, sobretudo, pela imitação, pelo exemplo. Nesta primeira época da vida não são os conhecimentos do educador que contam mas sim o seu carácter, a forma como acompanha a criança, como ele próprio se condu $z^{54}$. Os conhecimentos que comprovadamente possui são relevantes fundamentalmente a partir do segundo septénio, podendo "servir de base para concebir una verdadera metodología de la enseñanza y las condiciones vitales de la educación"55.

Com os mais pequenos estimula-se a brincadeira pela brincadeira, de preferência ao ar livre, no jardim, no meio da terra, das árvores e das plantas. 0 cuidado com o ambiente envolvente é relevante porque a beleza, o prazer e a alegria contribuem para um desenvolvimento físico e espiritual adequado. A tranquilidade, a suavidade dos sons e dos movimentos são muito estimulantes e, também por isso, as crianças são chamadas pela educadora com uma canção, que vai progressivamente aumentando de volume ou com um sininho que vai tocando, se estão no exterior. Não há gritos, há sons, palavras, canções.

Não importa se 0 ambiente é asséptico mas sim natural, devendo estimular a imaginação $0^{56}$. Os materiais disponíveis são pedaços de madeira, pedras, conchas, tecidos, pinhas, elementos não plastificados que podem ser utilizados em diversas situações. Não há, propositadamente, brinquedos acabados que imitam pessoas e objetos mais industrializados e o melhor exemplo disso são os bonecos, normalmente de tecido ou tricotados, bem como pequenos móveis e alguns utensílios de cozinha em madeira, em alumínio ou cortiça, ou seja, em materiais que aguçam o sentido do tato e que poderão ter várias utilidades, dependendo daquilo que a criança estiver a necessitar, a recriar.

\section{Segundo nascimento}

A leitura, a escrita e a aritmética iniciam-se apenas a partir dos sete anos, no segundo septénio. Dos sete aos catorze anos, período que abrange do $1^{\circ}$ ao $8^{\circ}$ ano de escolaridade há um professor, o "professor de classe", o "professor tutor"57. Toda a metodologia de trabalho deve ser pensada pelo professor tendo em conta a continuação do desenvolvimento da imaginação e das competências artísticas. 0 belo deve continuar a estar presente em qualquer atividade, seja ela qual for. Ensinar uma língua, História, Matemática ou Geogra-

\footnotetext{
53 "Seremos aos vinte anos o que fizerem de nós na infância", A Capital (25 de julho de 1985), 12.

${ }^{54}$ Ver Rudolf Steiner, The Child's Changing Consciousness. As the basis of pedagogical practice. Eight Lectures (Hudson, N.Y.: Anthroposophic Press, 1996), 64-65.

${ }^{55}$ Rudolf Steiner, La educación del niño desde el punto de vista de la Antroposofía, 67.

${ }^{56}$ Christel Makosh deu, no seu testemunho, vários exemplos de como se deveria estimular a imaginação das crianças.

${ }^{57}$ Warren Ashe et. al., Educação Waldorf - Introdução à Educação Waldorf de Rudolf Steiner, 8.
} 
fia deve incluir tanta criatividade e harmonia como ensinar Música, Canto ou Educação Física.

O trabalho deve ser sobretudo prático e com recurso fundamental a imagens, biografias, exemplos concretos, desenhos, canções. No caso da História, por exemplo, o objetivo é começar pela própria família, perceber quem são os seus diferentes elementos, de onde vieram, quando, e ir recuando no tempo de forma progressiva. A história da família é, portanto, estruturante e, por outro lado, procura-se construir uma narrativa de pessoas concretas que tenham vivido num certo período histórico, procurando perceber como vivia a gente comum e, também, aqueles que ficaram conhecidos por determinados acontecimentos que foram considerados relevantes ${ }^{58}$.

Não interessa nesta fase apelar excessivamente ao intelecto mas trabalhar com imagens e metáforas, estimulando as capacidades intuitivas ${ }^{59}$. Deve cultivar-se a capacidade de se emocionar, de se assombrar com o novo e com as experiências de outras pessoas, de imaginar situações, temperaturas, receios, porque desenvolver a "sensibilidade ante 0 prodigioso reforça as aptidões críticas"60 e esse é um objetivo permanente da educação Waldorf.

Também aqui, na idade da escolarização, o tempo não deve ser apressado. Tem de haver momentos para refletir, debater, compreender, experimentar, pôr em prática exercitando, desenhando, construindo uma narrativa escrita ou visual/gráfica. Desde os sete anos que os alunos são incentivados a elaborarem os seus manuais, os seus livros de textos, de apontamentos, que ilustram graficamente - são verdadeiros trabalhos de projeto muito pessoais que visam trabalhar diversas competências, da memorização, da síntese, da compreensão, ligadas entre si pela componente artística, pela harmonia entre as cores, pela linha e pelo traço, pela forma, pela capacidade de organização espacial da folha, pela transposição de imagens mentais. Ao assumirem-se como produtores de materiais escolares estão, também os alunos, a contrariar o serem apenas recetores acríticos de materiais produzidos por outros.

\section{Terceiro nascimento}

No terceiro septénio é que é suposto trabalhar conteúdos mais abstratos de Geografia, de Física, de Química, etc. Nesta fase trabalham-se conceitos abstratos mas sempre a partir de situações concretas, tentando-se que sejam compreendidas as conexões relativas a determinados contextos.

Procura-se que o estudante ganhe progressivamente autonomia, que ganhe confiança para emitir opiniões fundamentadas, aprendendo primeiro, julgando depois ${ }^{61}$. No entanto, a teoria conceptual só faz sentido se puder ser de algum modo concretizada e, por isso, a

\footnotetext{
${ }^{58}$ Ver Rudolf Steiner, Pédagogie et connaissance de l'homme, 62-63.

${ }^{59}$ Ver Rudolf Steiner, La educación del niño desde el punto de vista de la Antroposofía.

${ }^{60}$ Warren Ashe et. al., Educação Waldorf - Introdução à Educação Waldorf de Rudolf Steiner, 8.

${ }^{61}$ Rudolf Steiner, La educación del niño desde el punto de vista de la Antroposofía, 44.
} 
importância que é dada a trabalhos que possam integrar aprendizagens muito diferentes mas complementares. A propósito destas questões, Steiner dá o exemplo prático de partir do estudo das funções do fígado para compreender melhor alguns aspetos da civilização egípcia ${ }^{62}$.

Os alunos continuam a ilustrar os apontamentos ou os relatórios de experiências com desenhos diversos, representações gráficas, mapas, etc., e continuam a mobilizar-se capacidades distintas relacionadas com a síntese abstrata, com a criação artística, a motricidade fina, a geometria espacial. A teoria tem uma expressão prática concreta e é, desse modo, mais facilmente apropriada pelo estudante.

"Tudo na Escola Waldorf, desde o mobiliário da aula até à forma de recitar um poema, desde o tipo de lápis utilizado pelo aluno até aos exercícios no ginásio, se considera com dois critérios em mente: deve ser funcional ou útil e, além disso, belo"63. Por outro lado, não faz sentido que o professor trabalhe isolado, tendo em conta que o ensino centrado em áreas científicas e disciplinares "estanques" não existe, tal como não existe o conceito de "aula" ou de "classe". As atividades educativas devem ser pensadas em conjunto, envolvendo diversas informações com um objetivo muito claro que nunca abandona a espiritualidade como "base vital de toda a arte educativa"64 - a educação integral do ser humano.

\footnotetext{
${ }^{62}$ Rudolf Steiner, Pédagogie et connaissance de l'homme, 28.

${ }^{63}$ Warren Ashe et. al., Educação Waldorf - Introdução à Educação Waldorf de Rudolf Steiner, 8.

${ }^{64}$ Rudolf Steiner, La educación del niño desde el punto de vista de la Antroposofía, 34.
} 